\title{
Prediction of Daily and Lactation Yields of Milk, Fat, and Protein Using an Autoregressive Repeatability Test Day Model
}

\author{
J. Vasconcelos, ${ }^{1}$ A. Martins, ${ }^{2}$ M. F. Petim-Batista, ${ }^{3}$ \\ J. Colaço, ${ }^{3}$ R. W. Blake, ${ }^{4}$ and J. Carvalheira ${ }^{1,5}$ \\ ${ }^{1}$ CIBIO/ICETA, Centro de Investigação em Biodiversidade e Recursos Genéticos, \\ Universidade do Porto, Portugal \\ ${ }^{2} \mathrm{ABLN}$, Associação para o apoio à Bovinicultura Leiteira do Norte, Portugal \\ ${ }^{3}$ UTAD, Universidade de Trás-os-Montes e Alto Douro, Portugal \\ ${ }^{4}$ Department of Animal Science, Cornell University, Ithaca, NY 14853 \\ ${ }^{5}$ ICBAS, Instituto de Ciências Biomédicas Abel Salazar, \\ Universidade do Porto, Portugal
}

\begin{abstract}
We evaluated the accuracy of an autoregressive multiple-lactation test day (ATD) model to predict missing test day yields of milk, fat, and protein to obtain cumulative 305-d records for cows with incomplete or inprogress lactations. The data consisted of more than one million observations of daily yields on test days in the first 3 lactations of over 75,000 Portuguese Holstein cows. Differences between actual (estimates from complete lactations using the test interval method) and ATD-predicted 305-d yields were negligible and smaller than those predicted by the test interval method. The ATD procedure tended to slightly underestimate cumulative lactation yields, whereas the test interval method substantially overestimated them. Smaller differences obtained by the ATD procedure resulted in less biased estimates of lactation yield, which also implies greater accuracy. As expected, the correlations between actual and predicted lactation yields increased with the number of test days from 0.831 to 0.997 . Average correlations (by parity) between actual and ATD-predicted yields ranged from 0.977 to 0.984 . Correlations between actual test day yields and corresponding predicted yields exceeded 0.5 for up to 7 time-intervals from the last test day yield used to predict cumulative yield of projected lactations. These correlations indicate the good predictive ability of the ATD method. From a producer's viewpoint, these advantages underwrite management because most on-farm selection decisions are based on the producing abilities of cows. Implementation of ATD methodology does not require special computing capability and is easily transferable to the farm level.
\end{abstract}

Received February 5, 2004.

Accepted March 29, 2004.

Corresponding author: J. Carvalheira; e-mail: jgc3@mail.icav.up.pt.
(Key words: test day model, autoregression, dairy cattle, prediction of test day record)

Abbreviation key: ATD = autoregressive multiple lactations test day model, LTE = long-term environmental effect, $\mathbf{S T E}=$ short-term environmental effect, TD $=$ test day, $\mathbf{T I M}=$ test interval method.

\section{INTRODUCTION}

Daily yield on a test day (TD) is a potent source of information for dairy cattle genetic evaluation and herd management. Nonetheless, there are many situations in which estimates of cumulative 305-d yields are needed, especially for cow culling based on producing ability. Another reason for using estimates of cumulative yield is the limited capacity to process large amounts of TD data (Bormann et al., 2002; Wiggans et al., 2002), which may preclude direct use of TD records in genetic evaluation. For these cases, a classical 2-step approach of first estimating 305-d lactation yields of cows followed by genetic evaluation of sires and daughters is most practical because more individuals are considered (Bormann et al., 2002; Wiggans et al., 2002).

Although genetic evaluation based on TD records is under investigation in Portugal (Carvalheira et al., 2001, 2002), the official method to evaluate the dairy cattle population is based on cumulative 305-d lactation yields of milk and milk components. The Portuguese Dairy Cattle Breeders Association utilizes the test interval method (TIM) to estimate them from TD measurements, following the rules defined by the International Committee for Animal Recording (ICAR, 1995). Criteria for records to be used in genetic evaluation are restrictive. For example, the Portuguese national dairy database (primarily from the Holstein breed) annually accumulates about 90,000 valid 305d lactation records from approximately 104,000 cows with dry dates. Completed lactations must be at least 
Table 1. Variance components $\left(\mathrm{kg}^{2}\right)$ and autocorrelations for daily milk, fat, and protein yields for the Portuguese Holstein population.

\begin{tabular}{lrll}
\hline Component & Milk & Fat & Protein \\
\hline Error variance & 2.967 & 0.010 & 0.003 \\
LTE $^{1}$ variance & 7.995 & 0.015 & 0.006 \\
LTE autocorrelation $^{3}$ & 0.133 & 0.185 & 0.153 \\
STE $^{2}$ variance (L1) & 12.960 & 0.014 & 0.009 \\
STE autocorrelation (L1) $_{\text {STE variance (L2) }}^{3}$ & 0.830 & 0.687 & 0.766 \\
STE autocorrelation (L2) & 24.756 & 0.031 & 0.018 \\
STE variance (L3) & 0.828 & 0.639 & 0.792 \\
STE autocorrelation (L3) & 28.758 & 0.037 & 0.022 \\
\hline
\end{tabular}

${ }^{1} \mathrm{LTE}=$ Long-term environmental effects.

${ }^{2} \mathrm{STE}=$ Short-term environmental effects.

${ }^{3} \mathrm{~L} 1=1$ st lactation; L2 = 2nd lactation; L3 = 3rd lactation.

$305 \mathrm{~d}$ long or in-progress records must have at least 210 DIM to be projected to a 305-d basis (Gama et al., 2000). To illustrate information losses for genetic evaluations, about $23 \%$ of all lactations from 1994 to 2000 were ignored because they were too short or still in progress $(<210 \mathrm{DIM})$. Yet more information is lost because multiparous cows without recorded first lactation yields are also ignored. For small national data sets, like the case of Portugal, recovery of lost information is vital to genetic evaluation.

Several reports indicated that TIM might be less accurate than other methods to estimate cumulative 305-d yields (Schaeffer and Jamrozik, 1996; VanRaden, 1997; Norman et al., 1999; Pool and Meuwissen, 1999). Schaeffer and Jamrozik (1996) predicted lactation yields for milk, fat, and protein using a multipletrait procedure that incorporated standard lactation curves following Wood (1967) equation. This procedure permitted more accurate predictions of 305-d yields compared with the TIM regardless of the number of missing TD measurements. Pool and Meuwissen (1999) found that a 5th-order Legendre polynomial random regression TD model yielded the best fit and more accurate 305-d lactation predictions than TIM.

An alternative approach for estimating cumulative lactation yield is by a TD model with autoregressive structure (Carvalheira et al., 1998, 2002; Macciotta et al., 2002; Vasconcelos et al., 2002). Autoregressive multiple-lactation test day (ATD) models may predict cumulative yield within herd and parity, adjusted for herd management and age of cow, by accounting for long-term (correlations between parities) and shortterm (correlations between TD within a lactation) environmental effects (LTE and STE, respectively) governing repeated milking performance of a cow. Advantages of this method are that all TD residuals from incomplete or in-progress lactations can be predicted and cumulative yields estimated without need for projection factors by summing the appropriate within herd means. Thus, using the classic genetic evaluations, recuperating "lost" records would be expected to result in less biased genetic evaluations by permitting culled animals to contribute to their sire's evaluation, including the possibility for earlier evaluation of young sires (Henderson et al., 1959; Wiggans and Van Vleck, 1979; Norman et al., 1999). Therefore, the objective of this study was to evaluate the accuracy of the ATD model to predict missing TD yields of milk, fat, and protein and to estimate 305-d cumulative yields compared with standard TIM procedures.

\section{MATERIALS AND METHODS}

\section{Data}

Data provided by the Portuguese Dairy Cattle Breeders Association consisted of TD yields of milk, fat, and protein from Portuguese Holstein cows from June 1994 to December 2000. Monthly records (morning plus afternoon yields on the same day) from cows in the first 3 lactations in supervised recording plans were used. Lactations were required to have at least 2 TD records per cow. Further edits followed ICAR (1995) rules for TD recording. Briefly, TD records corresponded to the range of 5 to 305 DIM, first reported TD could not exceed 75 DIM, and time interval between consecutive TD has to be between 26 and $33 \mathrm{~d}$. Edited files contained 2,101,098, 2,093,524, and $2,103,506$ TD yields of milk, fat, and protein, respectively, from which data subsets were extracted for this study.

\section{Model}

The ATD model developed and applied by Carvalheira et al. (1998, 2002) was adapted to include a random cow effect partitioned into 2 autoregressive processes. One process accounted for correlations among TD within each lactation: STE. Long-term environmental effects were accounted by the correlations between lactations (parities). The TD yields within a lactation were treated as independent random variables with heterogeneous (co)variance components describing STE effects in each lactation. Genetic relationships among cows were assumed to be nil. However, this simplification of our model (Carvalheira et al., 1998, 2002) permits confounding of the genetic component with the LTE and STE effects. The ATD "cow" model used to analyze the TD data was as follows:

$$
\begin{aligned}
\mathrm{y}_{\mathrm{ijkLmn}} & =\mathrm{HTD}_{\mathrm{i}}+\operatorname{Age}(\mathrm{H})_{\mathrm{j}}+\operatorname{DIM}(\mathrm{H})_{\mathrm{k}(\mathrm{L})} \\
& +\mathrm{p}_{\mathrm{m}(\mathrm{L})}+\mathrm{t}_{\mathrm{n}(\mathrm{mL})}+\mathrm{e}_{\mathrm{ijkLmn}},
\end{aligned}
$$


Table 2. Frequency (\%) of complete (with 10 test day records) and incomplete or in-progress (2 to 9 test day records) milk lactations (L) obtained from the Portuguese dairy cattle database (from June 1994 to December 2000). ${ }^{1}$

\begin{tabular}{lccr}
\hline & \multicolumn{3}{c}{ Frequency $(\%)$} \\
\cline { 2 - 4 } Test days & L1 & L2 & L3 \\
\hline 2 & 4.0 & 4.2 & 4.6 \\
3 & 4.0 & 4.6 & 4.8 \\
4 & 4.0 & 4.6 & 4.7 \\
5 & 3.5 & 4.3 & 4.8 \\
6 & 3.6 & 4.4 & 4.5 \\
7 & 4.1 & 5.4 & 5.6 \\
8 & 6.9 & 8.6 & 8.4 \\
9 & 25.9 & 25.0 & 24.9 \\
10 & 44.0 & 38.9 & 37.7 \\
\hline 1
\end{tabular}

${ }^{1}$ Frequencies for fat and protein were similar.

where $y$ is the TD yield, HTD is the fixed effect of herdtest-date, Age $(\mathrm{H})$ is the fixed effect of age at calving (grouped in 16 classes from 18 to 76 mo of age) nested within herd $(\mathrm{H}), \mathrm{DIM}(\mathrm{H})$ is the fixed effect of DIM nested with herd and lactation number $(\mathrm{L}), \mathrm{p}$ is the random effect of LTE accounting for the correlations generated by the cow across lactations, $t$ is the random effect of STE accounting for the correlations due to the cow between TD within a lactation, and e is the random residual effect. The effects of $p$ and $t$ are fitted with first-order autocorrelation structures. Variance components and correlations were obtained using derivative free REML methodology (Smith and Graser, 1986) to estimate 9 parameters (5 variance components and 4 autocorrelations, Table 1 ).

Data subsets containing only complete lactations (i.e., those with 10 TD measurements) were extracted from the edited database for each trait to evaluate the predictive capacity of the ATD model. These complete datasets contained 1,048,730 (76,633), 1,024,020 $(75,252)$, and 1,048,150 $(76,553)$ TD records (cows) for milk, fat, and protein, respectively. Reduced datasets were created for each trait by randomly deleting TD records to mimic the pattern (frequency) of missing
TD measurements in the national database corresponding to incomplete or in-progress lactations (Table 2).

Cumulative 305-d lactation yields were estimated for both the complete and reduced datasets using ATD and TIM (based on the rules by ICAR [1995] methods). Projected yields by the TIM were for lactations with at least 210 DIM ( $\geq 7$ TD) and were based only on the last TD yield. The ATD method was applied to lactations with at least 2 TD measurements. Goodness of prediction was assessed by comparing cumulative 305-d lactations records obtained by these 2 methods for complete and reduced datasets. Measures of accuracy were correlations, means, and standard deviation of differences between ATD- and TIM-estimated yields.

\section{RESULTS AND DISCUSSION}

\section{Complete Lactations with 10 Test Days}

Means, standard deviations, and correlations between estimated lactation yields obtained by TIM and ATD for complete lactations with 10 daily yields on TD are given in Table 3. Estimated yields did not differ significantly for any trait $(P>0.5)$. Standard deviations were slightly smaller for the ATD method. Large correlations $(\geq 0.995)$ indicated that these methods have equal predictive value for cumulative yields when daily yields on all TD are available. Hereafter, TIM estimates of lactation yields from complete lactations are the basis for comparisons with yields projected from fewer TD measurements by either TIM or ATD.

\section{Incomplete and In-Progress Lactations}

Means and standard deviations of the difference between complete and projected lactation yields in each parity and correlations between them are given in Table 4 for milk, fat, and protein. Differences between complete and projected lactation yields by the ATD

Table 3. Means and standard deviations ${ }^{1}$ of 305 -d lactation (L) records of milk, fat, and protein (kg) obtained from the complete dataset (all 10 test day records available) using the test interval method (TIM) and autoregressive repeatability test day model (ATD), and their correlations.

\begin{tabular}{|c|c|c|c|c|c|c|c|c|c|}
\hline & \multicolumn{3}{|c|}{ Milk } & \multicolumn{3}{|c|}{ Fat } & \multicolumn{3}{|c|}{ Protein } \\
\hline & 1 st L & 2nd L & 3rd L & 1st L & 2nd L & 3rd L & 1st L & 2nd L & 3rd L \\
\hline TIM & $\begin{array}{c}7071.7 \\
(1426.8)\end{array}$ & $\begin{array}{c}7825.0 \\
(1669.3)\end{array}$ & $\begin{array}{c}7985.7 \\
(1641.6)\end{array}$ & $\begin{array}{c}252.6 \\
(55.2)\end{array}$ & $\begin{array}{c}277.3 \\
(63.7)\end{array}$ & $\begin{array}{c}283.7 \\
(63.5)\end{array}$ & $\begin{array}{c}223.5 \\
(45.8)\end{array}$ & $\begin{array}{l}248 \\
(52.1)\end{array}$ & $\begin{array}{c}250.2 \\
(51.1)\end{array}$ \\
\hline ATD & $\begin{array}{c}7057.9 \\
(1401.7)\end{array}$ & $\begin{array}{c}7804.9 \\
(1639.7)\end{array}$ & $\begin{array}{c}7965.4 \\
(1613.1)\end{array}$ & $\begin{array}{c}252.5 \\
(53.8)\end{array}$ & $\begin{array}{c}277.4 \\
(62.1)\end{array}$ & $\begin{array}{c}283.6 \\
(61.8)\end{array}$ & $\begin{array}{c}223.2 \\
(45.1)\end{array}$ & $\begin{array}{l}248 \\
(51.4)\end{array}$ & $\begin{array}{c}250.4 \\
(50.4)\end{array}$ \\
\hline Correlation & 0.998 & 0.997 & 0.995 & 0.998 & 0.997 & 0.995 & 0.998 & 0.997 & 0.995 \\
\hline
\end{tabular}

${ }^{1}$ Standard deviations are in parenthesis. 
Table 4. Means and SD of differences between actual ${ }^{1}$ and predicted 305-d milk, fat, and protein yields (kg), and correlations between actual and predicted lactation yields by autoregressive repeatability test day model (ATD) and test interval method (TIM).

\begin{tabular}{|c|c|c|c|c|c|c|c|c|c|c|c|c|c|c|c|c|c|c|}
\hline \multirow[b]{3}{*}{ Tests $^{2}$} & \multicolumn{6}{|c|}{ Milk } & \multicolumn{6}{|c|}{ Fat } & \multicolumn{6}{|c|}{ Protein } \\
\hline & \multicolumn{2}{|c|}{ Mean } & \multicolumn{2}{|c|}{$\mathrm{SD}$} & \multicolumn{2}{|c|}{ Correlation } & \multicolumn{2}{|c|}{ Mean } & \multicolumn{2}{|c|}{$\mathrm{SD}$} & \multicolumn{2}{|c|}{ Correlation } & \multicolumn{2}{|c|}{ Mean } & \multicolumn{2}{|c|}{$\mathrm{SD}$} & \multicolumn{2}{|c|}{ Correlation } \\
\hline & ATD & TIM & ATD & TIM & ATD & TIM & ATD & TIM & ATD & TIM & ATD & TIM & ATD & TIM & ATD & TIM & ATD & TIM \\
\hline & & & & & & & & & Lactat & n 1 & & & & & & & & 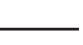 \\
\hline 2 & -4.5 & - & 702.24 & - & 0.860 & - & 0.27 & - & 29.41 & - & 0.856 & - & 0.31 & - & 23.45 & - & 0.861 & - \\
\hline 3 & -21.7 & - & 583.86 & - & 0.913 & - & 0.82 & - & 24.34 & - & 0.898 & - & -0.47 & - & 19.46 & - & 0.907 & - \\
\hline 4 & -2.5 & - & 485.03 & - & 0.940 & - & 0.97 & - & 20.47 & - & 0.928 & - & 0.13 & - & 16.24 & - & 0.934 & - \\
\hline 5 & -27.5 & - & 399.13 & - & 0.957 & - & 0.05 & - & 17.27 & - & 0.949 & - & 0.15 & - & 13.04 & - & 0.957 & - \\
\hline 6 & -1.9 & - & 318.58 & - & 0.976 & - & -0.09 & - & 14.00 & - & 0.967 & - & -0.52 & - & 10.39 & - & 0.974 & - \\
\hline 7 & -22.8 & 171.0 & 236.98 & 267.29 & 0.987 & 0.985 & 0.04 & 3.13 & 10.44 & 12.92 & 0.982 & 0.975 & -0.10 & 3.69 & 8.30 & 9.78 & 0.983 & 0.978 \\
\hline 8 & -18.4 & 90.5 & 172.03 & 175.71 & 0.993 & 0.993 & -0.09 & 1.90 & 8.06 & 9.22 & 0.990 & 0.987 & -0.19 & 2.31 & 5.74 & 6.18 & 0.992 & 0.991 \\
\hline 9 & -13.4 & 37.3 & 115.14 & 93.39 & 0.997 & 0.998 & -0.01 & 0.82 & 5.21 & 4.64 & 0.996 & 0.997 & -0.12 & 0.98 & 3.75 & 3.29 & 0.997 & 0.997 \\
\hline 2 & -3.6 & - & 799.97 & - & 0.877 & - & -0.22 & - & $\begin{array}{c}\text { Lactat } \\
3.45\end{array}$ & n 2 & 0.848 & - & -0.50 & - & 26.67 & - & 0.858 & - \\
\hline 3 & 4.4 & - & 688.23 & - & 0.912 & - & 1.04 & - & 28.81 & - & 0.887 & - & 1.28 & - & 21.77 & - & 0.909 & - \\
\hline 4 & -0.6 & - & 569.28 & - & 0.942 & - & 0.74 & - & 24.07 & - & 0.925 & - & -0.03 & - & 18.62 & - & 0.929 & - \\
\hline 5 & -14.4 & - & 453.76 & - & 0.961 & - & 0.54 & - & 20.70 & - & 0.945 & - & 0.58 & - & 15.89 & - & 0.953 & - \\
\hline 6 & -20.6 & - & 376.88 & - & 0.975 & - & 0.88 & - & 16.43 & - & 0.966 & - & 0.39 & - & 12.61 & - & 0.973 & - \\
\hline 7 & -17.6 & 337.7 & 287.93 & 327.40 & 0.984 & 0.983 & 0.38 & 8.80 & 13.01 & 15.81 & 0.979 & 0.973 & 0.08 & 8.55 & 9.61 & 10.85 & 0.983 & 0.980 \\
\hline 8 & -20.0 & 175.3 & 213.75 & 204.86 & 0.992 & 0.993 & 0.14 & 4.66 & 9.40 & 9.94 & 0.989 & 0.989 & 0.01 & 4.60 & 7.00 & 7.10 & 0.991 & 0.991 \\
\hline 9 & -18.6 & 61.9 & 148.43 & 102.78 & 0.996 & 0.998 & 0.05 & 1.76 & 6.20 & 4.80 & 0.995 & 0.997 & -0.01 & 1.70 & 4.58 & 3.54 & 0.996 & 0.998 \\
\hline 2 & -27.2 & - & 822.83 & - & 0.858 & - & 0.35 & - & 33.24 & - & 0.841 & - & -0.43 & - & 27.25 & - & 0.831 & - \\
\hline 3 & -9.6 & - & 684.57 & - & 0.909 & - & -0.69 & - & 30.15 & - & 0.889 & - & -0.22 & - & 23.36 & - & 0.892 & - \\
\hline 4 & -74.9 & - & 576.35 & - & 0.937 & - & 1.68 & - & 25.31 & - & 0.919 & - & -0.55 & - & 19.96 & - & 0.920 & - \\
\hline 5 & -1.7 & - & 478.00 & - & 0.958 & - & 0.46 & - & 21.21 & - & 0.945 & - & 1.65 & - & 16.05 & - & 0.945 & - \\
\hline 6 & -25.1 & - & 373.01 & - & 0.973 & - & -0.54 & - & 16.42 & - & 0.963 & - & -0.23 & - & 12.90 & - & 0.969 & - \\
\hline 7 & -14.0 & 365.9 & 299.43 & 340.14 & 0.983 & 0.982 & 0.20 & 10.14 & 13.67 & 16.12 & 0.976 & 0.971 & 0.23 & 9.56 & 9.62 & 10.96 & 0.982 & 0.980 \\
\hline 8 & -19.9 & 192.8 & 221.77 & 217.40 & 0.991 & 0.992 & -0.47 & 5.11 & 9.87 & 9.89 & 0.988 & 0.988 & 0.13 & 5.26 & 7.18 & 7.08 & 0.990 & 0.991 \\
\hline 9 & -14.9 & 65.9 & 150.77 & 99.02 & 0.996 & 0.998 & 0.04 & 1.95 & 6.79 & 4.85 & 0.995 & 0.997 & 0.14 & 1.77 & 4.89 & 3.50 & 0.996 & 0.998 \\
\hline
\end{tabular}

${ }^{1}$ Actual 305 -d milk yields corresponds to TIM estimates with all 10 test day records.

${ }^{2}$ Number of test days used for prediction of lactation yields. 
Table 5. Correlations between observed and $\mathrm{ATD}^{1}$-predicted test days (TD) for milk, fat, and protein yields in first lactation.

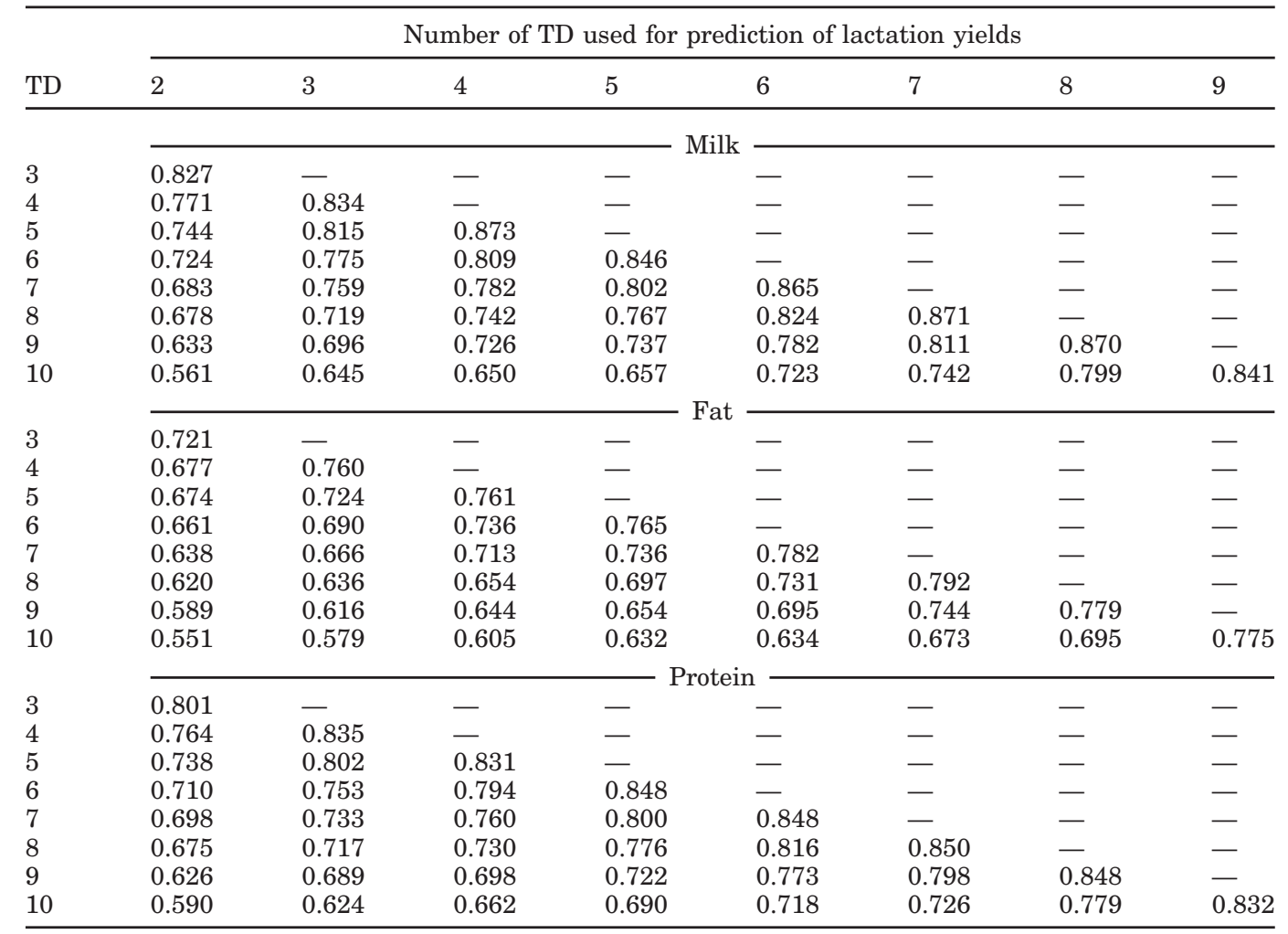

${ }^{1}$ Autoregressive repeatability test day model.

method were negligible and much smaller for all traits than those obtained using the TIM, which agrees with other reports (Schaeffer and Jamrozik, 1996; Norman et al., 1999; Macciotta et al., 2002). The available number of TD did not produce a discernible pattern in the mean differences. However, predictions by the TIM resulted in large differences in means and standard deviations of differences of actual complete and predicted 305-d yields with 7 TD measurements. These differences decreased with additional TD observations. Generally, the ATD method slightly underestimated (underprojected) lactation yields, especially for milk, whereas the TIM substantially overestimated them. In absolute terms, the smaller differences obtained with the ATD procedure are expected to result in less biased predictions of lactation yield, which signifies greater accuracy.

The standard deviations of the differences decreased with the available number of TD in all traits for both procedures, similar to other findings (Schaeffer and Jamrozik, 1996; Norman et al., 1999). The ATD method always obtained the smallest standard deviation with 7 TD measurements. Similar to the estimates obtained by best prediction procedures (VanRaden, 1997; Norman et al., 1999), lactation yields predicted by the ATD method had relatively smaller standard deviation because predicted TD were regressed toward the parity means within herds. A companion study of variance components estimated from ATD-projected lactation records (141,681 cows, sired by 8,189 bulls, unpublished data) resulted in heritabilities that were 5 to 7 percentage points larger for yields of milk, fat, and protein than TIM-projected records, agreeing with other reports (Swalve, 2000; Jensen, 2001; Bormann et al., 2002; Wiggans et al., 2002).

The correlations between yields from complete and predicted lactations increased from 0.831 to 0.997 with the available number of TD measurements. These coefficients were similar to the ones found by Macciotta et al. (2002), but are slightly larger than those reported by Schaeffer and Jamrozik (1996), especially for yields predicted with 2, 3, or 4 TD. Similar to previous findings (e.g., Norman et al., 1999), the average correlations by parity between complete lactation yields and ATD-predicted yields were 0.977 to 0.984 for all traits.

Correlations between actual daily yields on TD and ATD-predicted daily yields in first parity for milk and fat are given in Table 5. As expected, the largest correlations were found nearest to TD and decayed with the time interval to more distant TD toward the end 


\section{Milk}
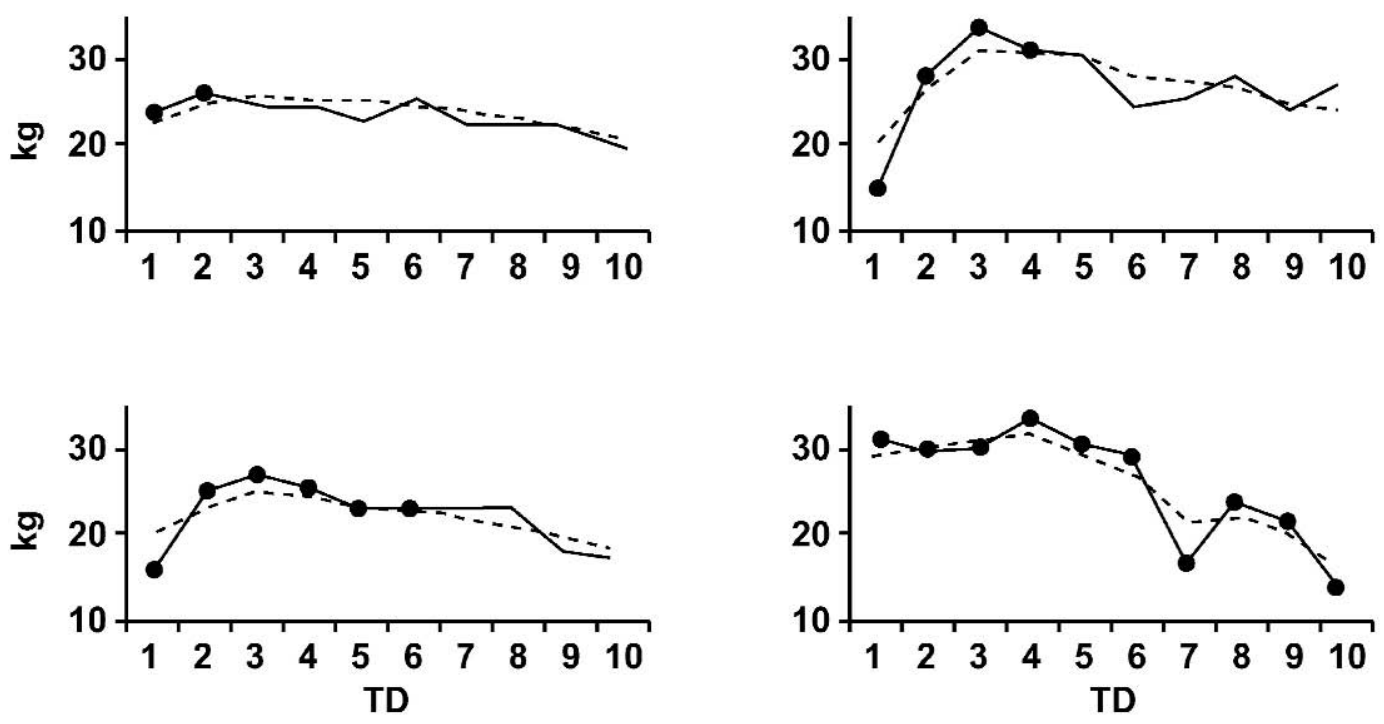

Fat
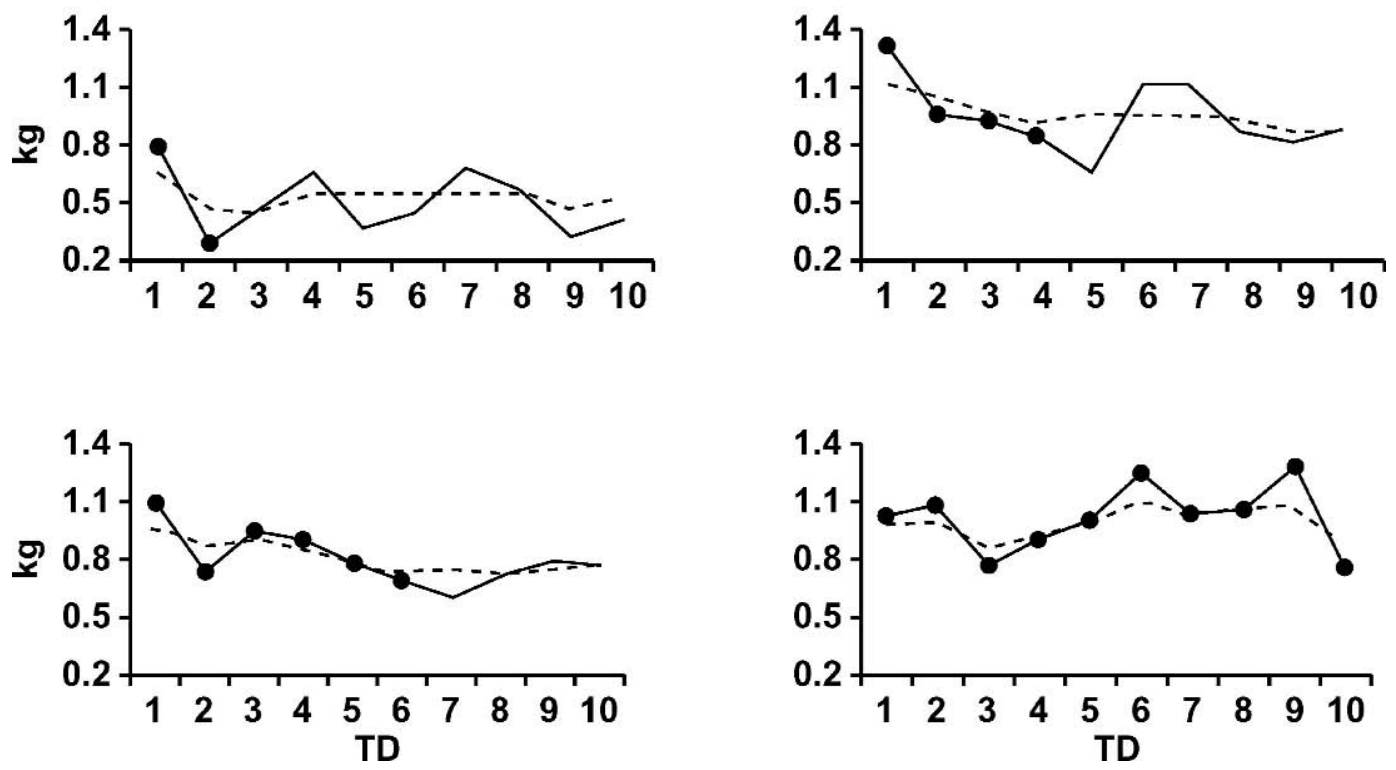

Figure 1. First lactation curves for milk and fat yields. Actual curve by autoregressive repeatability TD model based on $2,4,6$, and $10(\bullet)$ observed TD.

of lactation. Similar results were obtained for the 2nd and 3rd parities for all traits. Average correlations within parity for the first predicted TD yields were 0.84 to 0.86 for milk, 0.73 to 0.77 for fat, and 0.82 to 0.84 for protein, which were larger than correlations reported by Macciotta et al. (2002). Correlations between actual daily yields and predicted TD yields exceeded 0.5 up to 7 time intervals from the last actual
TD used in the prediction of the extended lactation. These relatively large correlations are an indirect measure of the predictive power of the ATD method.

Farmers need reliable information for management decisions, especially for cow culling. Shapes of lactation curves (e.g., presence or absence of detectable ascent to peak daily milk yield; Raffrenato et al., 2003) and information about lactation persistency of individ- 
ual cows are valuable management inputs. Besides cumulative 305-d lactation yields, accurate prediction of missing and expected TD yields permits graphical depiction of lactation curves for individuals and groups of cows, which are illustrated in Figure 1 for milk and fat in first lactation. These curves are from incomplete lactations that were projected based on varying numbers of available TD measurements. As VanRaden (1997) pointed out, the TIM is intended for simple interpolation, which may lead to poor prediction of distant TD yields. On the other hand, ATD-predicted lactation curves are adaptable to a wide range of data patterns. Regression of ATD-predicted TD yields toward the parity means within herd at each DIM helps ensure a good fit, even with only 2 TD available.

\section{CONCLUSIONS}

Dairy cattle evaluation systems based on 305-d cumulative lactation yields may benefit from TD methodology to predict complete lactations. This is especially important for situations similar to those in Portugal where incomplete and in-progress lactations are discarded from evaluations.

Differences between actual and predicted lactation yields by ATD were negligible and much smaller than those predicted by TIM for all 3 traits. In absolute terms, the smaller differences obtained from the ATD procedure resulted in less biased prediction, which also implies greater accuracy with this method. For these Portuguese data, it will be possible to recuperate all records from incomplete and in-progress lactations (between 23 and 30\%) that the traditional TIM procedure would have discarded for a genetic evaluation. Furthermore, genetic analysis performed on ATD-predicted 305-d lactation yields using the Portuguese national dataset resulted in heritabilities that were 5 to 7 percentage points larger than TIM-predicted records for all traits. The possibility of double counting when using ATD-predicted 305-d lactation records for genetic evaluations with the standard repeatability animal model was empirically tested by comparing the pattern and magnitude of the correlations between all combinations of real and ATD-predicted lactation records. No significant differences were found. However, additional model checking is required to assure this outcome. Our next step will be to use the animal model version of the ATD to fully describe the genetic component (Carvalheira et al., 2002). It is expected that this procedure will further increase the accuracy of predictions. The implementation of the ATD methodology does not require special computer power and would be easily transferred to the farm level.

\section{ACKNOWLEDGMENTS}

The authors thank A. Silvestre from Trás-os-Montes e Alto Douro University and A. Ferreira from the Portuguese Dairy Cattle Breeders Association for their assistance. This work contributes to project POCTI/ $33162 / C V T / 2000$ and was partially funded by the Fundação para a Ciência e a Tecnologia (FCT) and FEDER (EU).

\section{REFERENCES}

Bormann, J., G. R. Wiggans, T. Druet, and N. Genglar. 2002. Estimating effects of permanent environment, lactation stage, age, and pregnancy on test-day yield. Available: http://www.adsa.org/ jds/abs/2002/d0210263.htm. Accessed Dec. 2003.

Carvalheira, J., R. W. Blake, E. J. Pollak, R. L. Quaas, and C. V. Duran-Castro. 1998. Application of an autoregressive process to estimate genetic parameters and breeding values for dairy milk yield in a tropical herd of Lucerna cattle and in US Holstein herds. J. Dairy Sci. 81:2738-2751.

Carvalheira, J., E. J. Pollak, R. L. Quaas, and R. W. Blake. 2001. Fitting multiple-lactation test-day records with an autoregressive repeatability animal model. Page 6 in Proc. 52nd Annu. Meeting of the Eur. Assoc. for Anim. Prod., Budapest, Hungary.

Carvalheira, J., E. J. Pollak, R. L. Quaas, and R. W. Blake. 2002. An autoregressive repeatability animal model for test-day records in multiple lactations. J. Dairy Sci. 85:2040-2045.

Gama, L. T., I. Carolino, and N. Carolino. 2000. Correlações genéticas e fenotípicas entre a produção de leite e gordura em bovinos da raça Frísia. Page 104 in Proc. Congresso de Zootecnia, Estação Zootécnica Nacional, Vale de Santarém.

Henderson, C. R., O. Kempthorne, S. R. Searle, and C. M. von Krosigk. 1959. The estimation of environmental and genetic trends from records subject to culling. Biometrics 15:192-218.

ICAR. 1995. Recording Guidelines. Appendices to the information agreement of recording practices (milk recording). Int. Committee for Anim. Rec., Rome, Italy.

Jensen, J. 2001. Genetic evaluation of dairy cattle using test-day models. J. Dairy Sci. 84:2803-2812.

Macciotta, N. P. P., D. Vicario, G. Pulina, and A. Cappio-Borlino. 2002. Test day and lactation yield predictions in Italian Simmental cows by ARMA methods. J. Dairy Sci. 85:3107-3114.

Norman, H. D., P. M. VanRaden, J. R. Wright, and J. S. Clay. 1999. Comparison of test interval and best prediction methods for estimation of lactation yield from monthly, a.m.-p.m., and trimonthly testing. J. Dairy Sci. 82:438-444.

Pool, M. H., and T. Meuwissen. 1999. Prediction of daily milk yields from a limited number of test days using test day model. J. Dairy Sci. 82:1555-1564.

Raffrenato, E., R. W. Blake, P. A. Oltenacu, J. Carvalheira, and G. Licitra. 2003. Genotype by environment interaction for yield and somatic cell score with alternative environmental definitions. J. Dairy Sci. 86:2470-2479.

Schaeffer, L. R., and J. Jamrozik. 1996. Multiple-trait prediction of lactation yields for dairy cows. J. Dairy Sci. 79:2044-2055.

Smith, S. P., and H. U. Graser. 1986. Estimating variance components in a class of mixed models by restricted maximum likelihood. J. Dairy Sci. 69:1156-1165.

Swalve, H. 2000. Theoretical basis and computational methods for different test-day genetic evaluation methods. J. Dairy Sci. 83:1115-1124.

VanRaden, P. M. 1997. Lactation yields and accuracies computed from test day yields and (co)variances by best prediction. J. Dairy Sci. 80:3015-3022. 
Vasconcelos, J., A. Martins, M. F. Petim-Batista, A. Silvestre, A. Ferreira, J. Colaço, and J. Carvalheira. 2002. Estimation of lactation yields from test day yields of milk, fat, and protein for Portuguese Holstein cattle using an autoregressive test day model. Communication no. 01-57 in Proc. 7th World Congr. Genet. Appl. Livest. Prod., Montpellier, France. CD-ROM.

Wiggans, G. R., and L. D. Van Vleck. 1979. Extending partial lactation milk and fat records with a function of last-sample production. J. Dairy Sci. 62:316-325.
Wiggans, G. R., P. M. VanRaden, J. Bormann, J. C. Philpot, T. Druet, and N. Gengler. 2002. Deriving lactation yields from testday yields adjusted for lactation stage, age, pregnancy, and herd test date. http://www.adsa.org/jds/abs/2002/d0210264.htm. Accessed Dec. 2003.

Wood, P. 1967. Algebraic model of the lactation curve in cattle. Nature 216:164-165. 